\title{
Adaptability of cut rose (Rosa hybrida L.) varieties for shade and high temperature conditions in tropical greenhouses
}

\author{
R.L. Rupasinghe', W.B.W.M.R.C.P. Auluvihare', S.M.M.R. Mawalagedera², \\ W.A.P. Weerakkody ${ }^{1^{*}}$, P.R.S.D. Bandaranayake ${ }^{1}$ and L.D.B. Suriyagoda ${ }^{1}$
}

\begin{abstract}
Rose (Rosa hybrida L.) is one of the most popular cut flower species grown under protected culture in the world. However, in Sri Lanka, the commercial cultivation is limited to upcountry region due to low temperature. Even though many rose varieties are grown in relatively warm regions, their growth rates and productivity vary due to the lack of adaptability to temperature stress. Therefore, this research was conducted to identify adaptable varieties for moderately high temperature and partial shade in a replicated greenhouse research in Mid Country Wet Zone (MCWZ) and Intermediate Zone (MCIZ) of Sri Lanka. Rose varieties Black Magic and White Success were identified to be more adoptable to warm and humid greenhouse conditions in the MCWZ and $\mathrm{MClZ}$ during Yala season with respect to plant growth and flower yield. However, White Success was comparatively lower in marketable flower percentage and flower quality, compared to Black Magic. Cut flower varieties, Grand Gala and Peach Pope showed longer shelf-life compared to Black Magic and White Success. The types of shades, Aluminet (25\%) and black shade net (50\%), reduced the mean daytime temperature difference to $2.1 \pm 0.13$ between greenhouse air and outside air. The rose varieties Black Magic, Grand Gala and White Success could successfully be grown to obtain a good quality flower yield under the shade of Aluminet (25\% shade) in the greenhouse. The recognized the adaptability of the selected rose varieties to tropical greenhouse conditions, and the potential use of Aluminet ( $25 \%$ shade) as a temperature control measure in rose-producing greenhouses.
\end{abstract}

Keywords: Cut roses, flower yield, greenhouse cooling, shade netting, protected culture

\section{Introduction}

Rose (Rosa hybrida L.) is known as "Queen of the flowers" and occupies a special position in floriculture industry. Proper planning and crop management is essential to obtain blooms of good quality (Biswas, 1983). Because of being temperate origin with preference towards mild temperatures, cut rose is mainly grown in highlands of the central province of Sri Lanka (Dhanasekera, 1998). Climatic factors play a vital role in the production of quality roses. With the optimization of other resources, roses can be successfully grown under a range of high temperatures in low elevations. Even though many rose varieties are grown in high temperature regions, their growth rates and productivity vary due to the lack of adaptability to

\footnotetext{
1 Department of Crop Science, Faculty of Agriculture, University of Peradeniya, Sri Lanka

2 Faculty of Agriculture, Rajarata University of Sri Lanka, Puliyankulama, Sri Lanka

* Corresponding author: palithaw@pdn.ac.lk
} 
temperature stress. Though Manjula (2005) has reported results of varietal evaluation under naturally-ventilated poly-house in India, the published data on the adaptability of rose varieties under a range of environmental and agronomic conditions in Sri Lanka is scarce. The commercial growers of cut rose often experience production failures mainly due to inappropriate variety selection for warm climatic regions. Meanwhile, shading has been identified as a cost-effective temperature control measure in Sri Lankan protected culture, subjected to use of shade tolerant crop species (Weerasinghe et al., 2011). Therefore, this research was conducted to study the adaptability of selected cut rose varieties to greenhouse conditions and test their response to shade net imposed temperature control in the Mid Country Wet and Intermediate Zones of Sri Lanka.

\section{Materials and Methods}

The study was conducted under greenhouse conditions at Peradeniya in the Mid Country Wet Zone (MCWZ; agro-ecological region $\mathrm{WM}_{2 \mathrm{~b}}$ ) during May-August (Yala season) 2012 and at Dodangolla, Kundasale in the Mid Country Intermediate Zone MCIZ; agro-ecological region $\mathrm{IM}_{1 \mathrm{a}}$ ) during September-February (Maha season) 2013/2014 in the Kandy district of Sri Lanka. The annual average temperature of the two study locations was around $24^{\circ} \mathrm{C}$ and $28^{\circ} \mathrm{C}$, respectively.

The experiment I (Expt. I) conducted at Peradeniya used five rose varieties in four replicates. Two-month old, bud-grafted rose varieties Black Magic, Grand Gala, White Success, Grand Masterpiece and Peach Pope were planted and maintained in drip-fertigated grow-bags (filled with soil:cowdung:sand 5:4:2 w/w/w) as per standard procedures for commercial rose cultivation under greenhouses in Sri Lanka. The experiment II (Expt. II) conducted at Dodangolla was laid as a two-factor factorial in a Split-plot design. Three shade levels (i.e. main-plot factor), namely Aluminet ( $25 \%$ shade), Black shade net ( $50 \%$ shade) and without shade, and three rose varieties (Black Magic, Grand Gala, White Success) were used. The varieties (i.e. sub-plot factor) were selected based on their performance in the Expt. I. The experiment consisted of three replicates.

In both experiments, plant height, leaf area, leaf number, shoot number, time to flowering, flower counts, flower bud length, flower diameter, flower stalk length and the shelf-life were assessed. Data were analyzed using Statistical Analysis System (SAS) using ANOVA and CATMOD procedures, respectively. Mean separation was done using the Least Significant Difference (LSD) at $p=0.05$.

\section{Results and Discussion}

\section{Experiment I: Variety evaluation}

Vegetative Growth: Rose varieties Black Magic and White Success demonstrated a significantly higher plant growth $(p<0.05)$ in terms of leaf area from the initial 
growth stages. Varieties Grand Gala and Grand Masterpiece also formed significantly high leaf area $(p<0.05)$ compared to that of Peach Pope (Figure 1). These varietal differences in leaf area may be a result of leaf numbers rather than leaf size, where the varietal difference in leaf number was also statistically significant $(p<0.05)$ and showed the same pattern. Black Magic and White Success formed 22-27 leaves at 12 weeks after first pruning (WAP) while Grand Gala and Grand Masterpiece showed 1214 leaves.The shoot numbers of varieties Black Magic and White Success were relatively higher than that of other varieties (i.e. more than three shoots at 12 WAP). Grand Gala also showed similar number of shoot numbers up to 8 WAP but, declined thereafter to shoot mortality (data not shown).

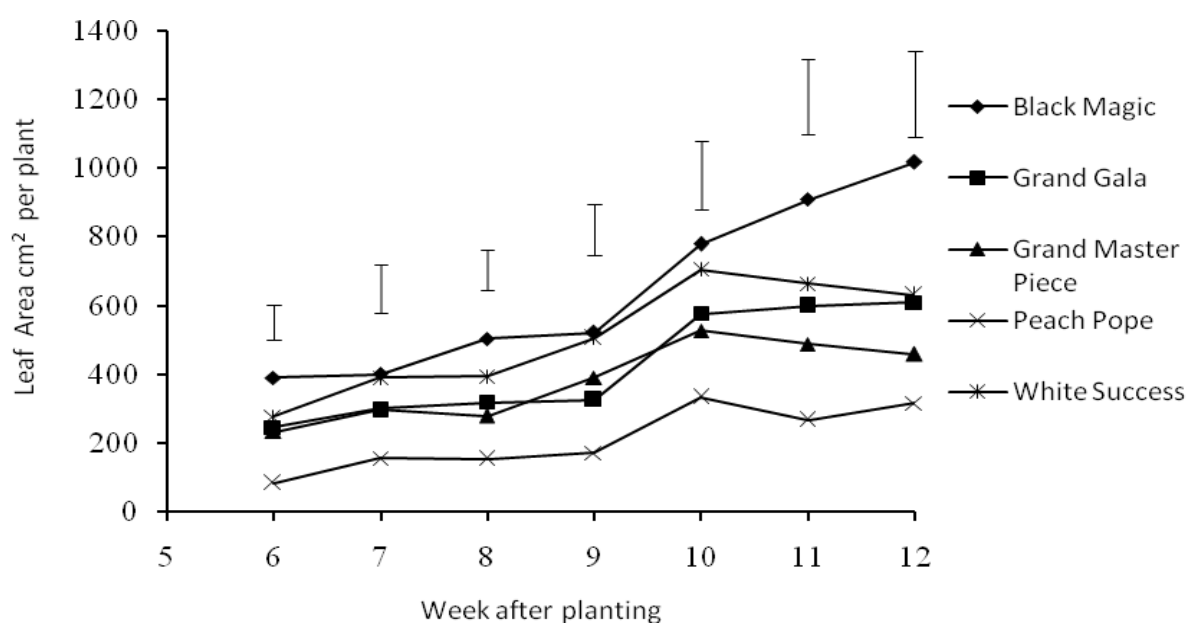

Figure 1. Leaf area of cut rose varieties at different growth stages when grown in greenhouse conditions at Peradeniya (Mid Country Wet Zone - MCWZ) of Sri Lanka. Vertical bars indicate LSD at $p=0.05$

Plant height of White Success was significantly lower than that of Black magic and Grand Gala at the end of 12-week growth period $(p<0.05)$. This could be a result of comparatively high shoot formation in this variety. In contrast, the varieties showing lower shoot numbers (i.e. Grand Masterpiece and Peach Pope) were significantly lower $(p<0.05)$ in plant height throughout the growth period (Figure 2$)$, which could be due to inherently low shoot growth rate of these two varieties.

Reproductive growth: A reasonably good flower quality (diameter, length and stalk length) was recorded in all test varieties while the flower yield (marketable flower number) was significantly higher $(p<0.05)$ in the two well grown varieties, Black Magic and White Success. Despite vigorous growth, significantly low flower yield in Grand Gala $(p<0.05)$ could be a result of its shoot mortality during the latter part of the growth. Three leading cut rose varieties namely, Black Magic, White Success and Grand Gala, showed a reasonably long shelf-life (more than four days) when grown 
under greenhouse conditions in the MCDZ (Table 1). However, cut flowers of Grand Gala and Peach Pope showed a longer shelf-life (more than 6.5 days) meeting the market requirements.

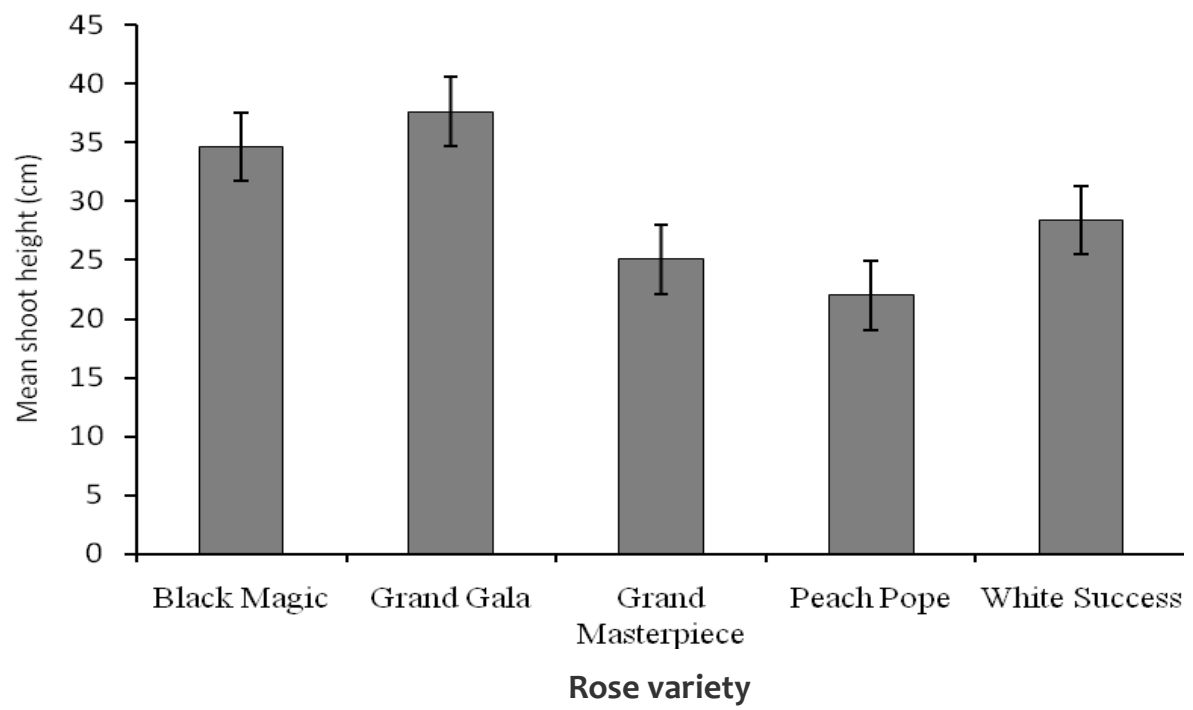

Figure 2. Plant height of cut rose varieties (at 12 weeks after pruning practice) under glasshouse conditions at Peradeniya (Mic County Wet Zone - MCWZ). Vertical bars indicate LSD at $\mathrm{p}=0.05$.

Table 1. Reproductive growth parameters of rose flowers grown under greenhouse conditions at Peradeniya (Mid Country Wet Zone - MCWZ)

\begin{tabular}{lccccc}
\hline Rose Variety & $\begin{array}{c}\text { Flower } \\
\text { diameter } \\
(\mathrm{cm})\end{array}$ & $\begin{array}{c}\text { Flower } \\
\text { length } \\
(\mathrm{cm})\end{array}$ & $\begin{array}{c}\text { Flower } \\
\text { stalk } \\
\text { length } \\
(\mathrm{cm})\end{array}$ & $\begin{array}{c}\text { Flower yield } \\
\text { (per plant)* }\end{array}$ & $\begin{array}{c}\text { Shelf-life } \\
\text { of flowers } \\
\text { (Days) }\end{array}$ \\
\hline Black Magic & $8.9^{\mathrm{b}}$ & $5.3^{\mathrm{a}}$ & 27.8 & $2.7(3.4)^{\mathrm{a}}$ & 4.34 \\
Grand Gala & $7.7^{\mathrm{c}}$ & $3.2^{\mathrm{c}}$ & 30.3 & $0.33(0.6)^{\mathrm{c}}$ & 6.5 \\
Grand Masterpiece & $10.6^{\mathrm{a}}$ & $4.3^{\mathrm{b}}$ & 28.6 & $0.75(0.9)^{\mathrm{bc}}$ & 3.88 \\
Peach Pope & $8.5^{\mathrm{bc}}$ & $3.6^{\mathrm{bc}}$ & 26.9 & $0.75(1.1)^{\mathrm{bc}}$ & 7.25 \\
White Success & $8.1^{\mathrm{bc}}$ & $4.1^{\mathrm{b}}$ & 22.4 & $1.04(2.2)^{\mathrm{b}}$ & 4.05 \\
LSD (p=0.05) & 1.07 & 0.6 & 7.3 & & \\
\hline
\end{tabular}

* Marketable flower yield; values within parenthesis represent the total flower yield. Within a column, means followed by the same letter are not significantly different at $p=0.05$.

\section{Experiment II: Effect of shading}

Internal Environment: The difference in temperature and light intensity in between the greenhouse (with shade netting) and outside in the $\mathrm{MCIZ}$ are illustrated in Figure 3. The mean temperature difference between inside and outside could be maintained at $2.07 \pm 0.13^{\circ} \mathrm{C}$ during daytime (Figure 3a). As illustrated in Figure $3 \mathrm{~b}$, the 
percentage light intensity in the greenhouse could be maintained at $75 \%$ ( $25 \%$ shade) under Aluminet (thermal screen) and at 50\% (50\% shade) under the black shade net.
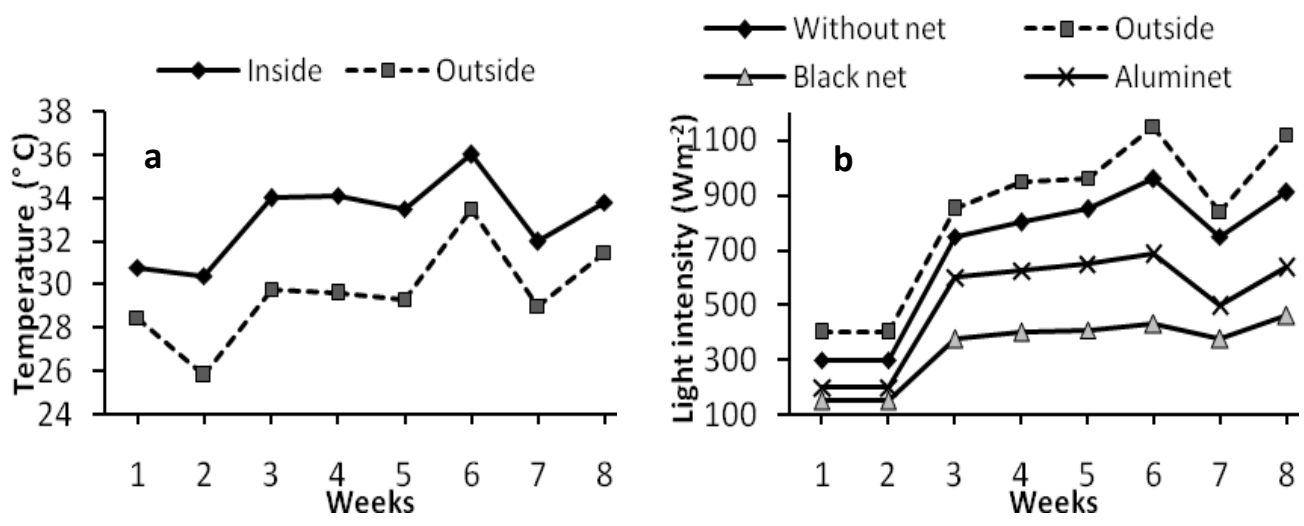

Figure 3. Temperature (a) and light intensity (b) under shade in the greenhouse during daytime in the Mid Country Intermediate Zone of Sri Lanka

Vegetative growth: The plant height and lead area of cut rose varieties did not show a significant difference ( $p>0.05$ ) when grown under $25 \%$ shade (Aluminet) at MCIZ. However, $50 \%$ shade (black hade net) resulted in a significantly lower plant height $(p<0.05)$ of all the tested varieties, compared to that of the $25 \%$ shade (Table 2 ). Similar results were observed for leaf area measurements for varieties, Black Magic and White Success (Table 2).

Table 2. Plant height and leaf area of cut rose varieties under different levels of shade under greenhouse conditions at Dodangolla (Mid Country Intermediate Zone - MCIZ).

\begin{tabular}{|c|c|c|c|}
\hline \multirow{2}{*}{ Rose Variety } & Without shade & $25 \%$ shade & $50 \%$ shade \\
\hline & \multicolumn{3}{|c|}{ Plant height $(\mathrm{cm})$} \\
\hline Grand Gala & $25.1 \pm 2.3^{\mathrm{ab}}$ & $29.4 \pm 3.5^{a}$ & $20.6 \pm 3.0^{b c}$ \\
\hline White Success & $22.8 \pm 2.3^{b}$ & $28.8 \pm 1.6^{a}$ & $18.9 \pm 3.0^{b c}$ \\
\hline \multirow[t]{2}{*}{ Black Magic } & $24.7 \pm 2.6^{\mathrm{ab}}$ & $28.7 \pm 2.2^{\mathrm{a}}$ & $18.8 \pm 2.0^{c}$ \\
\hline & \multicolumn{3}{|c|}{ Leaf area $\left(\mathrm{cm}^{2}\right)$} \\
\hline Grand Gala & $127.5 \pm 3.0^{a}$ & $107.6 \pm 6.1^{b}$ & $91.9 \pm 9.6^{c}$ \\
\hline White Success & $108.8 \pm 6.4^{\mathrm{ab}}$ & $114.6 \pm 4.9^{a}$ & $105.0 \pm 10.7^{\mathrm{ab}}$ \\
\hline Black Magic & $118.3 \pm 7.0^{\mathrm{ab}}$ & $125.4 \pm 6.9^{a}$ & $106.5 \pm 8.2^{b}$ \\
\hline
\end{tabular}

Within a column, means followed by the same letter are not significantly different at $\mathrm{p}=0.05$

In contrary to the results of Expt. I conducted at Peradeniya (MCWZ), the varietal differences in plant height in Expt. II (Dodangolla, MCIZ) was not statistically significant ( $p>0.05)$. However, similar to the results of Expt. I, variety Black Magic appeared to form a greater leaf area compared to that of White Success under 
greenhouse conditions, irrespective of the degree of shading (Table 2). Meanwhile the effects of shading and varietal differences on other vegetative growth parameters such as shoot number, leaf number and leaf colour were not statistically significant (data not shown). Lack of varietal differences in these growth parameters could be a result of variable plant response temperature (Yan et al., 2011). The day temperature prevailed in the greenhouse in the present study was high $(33.0 \pm 1.5$ $\left.{ }^{\circ} \mathrm{C}\right)$.

Reproductive Growth: As shown in Table 3, the flower yield and quality of cut rose varieties were significantly different $(p<0.05)$ under different shade levels. All test varieties formed the highest flower yield (a mean of $2.6 \pm 0.4$ flowers per plant) and flower diameter (a mean of $8.8 \pm 0.5 \mathrm{~cm}$ ) under $25 \%$ shade imposed by Aluminet.

Table 3. Flower yield and stalk length of cut rose varieties under different levels of shade under greenhouse condition at Dodangolla (Mid Country Intermediate Zone - MCIZ)

\begin{tabular}{|c|c|c|c|}
\hline \multirow{2}{*}{ Rose Variety } & Without shade & $25 \%$ shade & $50 \%$ shade \\
\hline & \multicolumn{3}{|c|}{ Number of flowers/plant } \\
\hline Grand Gala & $1.4 \pm 0.1^{b}$ & $2.2 \pm 0.2^{\mathrm{a}}$ & $1 \pm 0^{b}$ \\
\hline White Success & $1.7 \pm 0.2^{b}$ & $2.1 \pm 0.1^{\mathrm{a}}$ & $1.3 \pm 0^{b}$ \\
\hline \multirow[t]{2}{*}{ Black Magic } & $2.1 \pm 0.1^{\mathrm{ab}}$ & $2.6 \pm 0.4^{a}$ & $1.2 \pm 0.2^{\mathrm{b}}$ \\
\hline & \multicolumn{3}{|c|}{ Flower diameter $(\mathrm{cm})$} \\
\hline Grand Gala & $6.5 \pm 0.2^{b}$ & $7.5 \pm 0.4^{a}$ & $5.3 \pm 0.3^{c}$ \\
\hline White Success & $7.0 \pm 0.1^{b}$ & $8.8 \pm 1.0^{a}$ & $5.6 \pm 0.3^{c}$ \\
\hline Black Magic & $7.1 \pm 1.2^{\mathrm{ab}}$ & $8.0 \pm 1.5^{a}$ & $5.4 \pm 0.5^{c}$ \\
\hline
\end{tabular}

Within a column, means followed by the same letter are not significantly different at $p=0.05$.

Flower yield and flower diameter of Grand Gala and White Success were significantly higher $(p<0.05)$ while that of Black Magic was not significant different $(p>0.05)$ under $25 \%$ shade compared to without shade. However, the lowest yield and flower diameter shown by all three varieties at $50 \%$ shade (imposed by black shade net) indicated its inappropriateness as a temperature control tool in the greenhouse (Table 3). The mean flower bud height $(3.4 \pm 0.0 \mathrm{~cm})$ and the time for bud formation (30 \pm 2.3 days) were also higher under $25 \%$ shade in all three varieties tested (data not shown). Meanwhile, the variety Black Magic showed the highest number of flowers (1.9 \pm 0.6 per plant) and the shortest time taken for bud formation $(36.3 \pm 5$ days), followed by White Success (with or without shade) under greenhouse conditions in the MCIZ (Table 3).

\section{Conclusion}

Rose varieties Black Magic and White Success are more adoptable to warm and humid greenhouse conditions prevailed in the Mid Country Wet and Intermediate 
Zones in terms of plant growth and flower yield. However, marketable flower \% and flower quality of the variety White Success was comparatively lower compared to those of Black Magic. Shading (25-50 \%) reduced the mean daytime temperature difference to $2.1 \pm 0.13^{\circ} \mathrm{C}$ between greenhouse air and outside air in the Mid Country Intermediate Zone. The selected rose varieties Black Magic, Grand Gala and White Success maintained a substantially good vegetative and reproductive growth under reduced temperature and light shade provided by Aluminet in the greenhouse. The study recognized the adaptability of these rose varieties to tropical greenhouse conditions and the potential use of Aluminet ( $25 \%$ shade) as a temperature control measure in cut rose production in greenhouses.

\section{Acknowledgement}

Authors wish to acknowledge the sponsorship of Sir Lanka Council for Agricultural Research Policy (SLCARP) of the Ministry of Agriculture, and the support extended by Mr. P. Amarasekara, and Drs. C.K. Benaragama and J.W. Damunupola.

\section{References}

Biswas, T.D. (1983): Rose Growing Principles and Practices, Ass. Publ. Co., New Delhi.

Dhanasekera, D.M.U.B. (1998): Cut flower production in Sri Lanka. Available at http://www.fao.org/docrep/005/ac452e/ac 452e00 [Accessed on $29^{\text {th }}$ March 2012].

Manjula G. (2005): Performance of rose cultivars under naturally ventilated Poly-house. M.Sc. project report, Department of Horticulture, University of Agricultural Science, Dharwad, Available at http://www.etd.usad.edu/ft/th 522.pdf [Accessed on 29 ${ }^{\text {th }}$ March 2012]

Weerasinghe, K.W.L.K., Sooriyagoda, L.D.B. and Weerakkody, W.A.P. (2011): Combined and individual effects of forced-air ventilation, thermal covering and misting on greenhouse environment control. Sri Lankan J. Agri. Sci. 48: 18-28.

Yan H., Deng, J., Deng, J.Y., Li, L., Wan, Z. and Lin, W.P. (2011): Adaptability of newly introduced China rose in Southern Guangxi. J. South. Agri. 42 (11): 1371-1374. 
Rupasinghe et al. 